\title{
The Lymph Node Metastasis in Gastric Cancer and Ratio of Metastatic Lymph Nodes (RLN)
}

\author{
Kiss Lorant*, Kiss Roland, Kovács Csilla and Castilia Dobra \\ University Lucian Blaga of Sibiu, Emergency Academic Hospital of Sibiu, Romania
}

Submission: April 12, 2019; Published: May 13, 2019

"Correspondence Author: Kiss Lorant, University Lucian Blaga of Sibiu, Emergency Academic Hospital of Sibiu, Ist Surgical Clinic, Ist Medical Clinic, Romania

\section{Abstract}

Introduction: The routine identification and removal of regional lymph nodes (LN) in solid neoplasms is essential. The proportion between metastatic and examined lymph nodes ( $\mathrm{N}$-ratio) has been proposed as an independent prognostic factor in patients with gastric cancer. We analyzed the postoperative survival of 124 patients with gastric cancer, having 96 intraoperative lymphography with colorant (methyl blue). For lymph nodes status (N, PN), were assigned two classifications: TNM, UICC/AJCC and the JSCA: (NR0: 0\%, NR1 $\leq 20 \%$, NR2 >20\%). The impact concerning staging and survival of patients with gastric cancer and R0 resection was compared in the study group. A total of 124 patients with gastric cancer from our institution were studied retrospectively between 1998 and 2007.

Results: A significant difference in survival was in patients with NR1 versus NR2. In our multivariate analysis study, only NR with pT and histologically G (grading) were found to be independent prognostic factors. With JSCA classification, in patients with gastric cancer operated between 2000 and 2007, stage migration was present in 43 cases (51\%), with the UICC/AJCC TNM classification, in patients operated between 1998 and 2007, 15 cases (18\%) and when NR was applied, stage migration was found only in 14 (11\%) of cases.

Conclusion: The NR is a simply reproducible staging system, with a very good prognostic semnification.

Keywords: Gastric cancer; Lymph nodes; Staging

\section{Introduction}

The prognostic significance of the number of metastatic lymph nodes $(\mathrm{N}+)$ with gastric cancer has been revealed by several reports and some authors suggested that the number of lymph nodes with metastasis exerts a larger effect on survival than the anatomic level of involved nodes [1-4]. Anatomical distribution of regional lymph nodes is determined by the JSCA [5], but the numbering ( $\mathrm{N}=1-16)$ and grouping ( $\mathrm{Gr} 1-3)$ depends of the location and extension of tumors and it is too complicated to be used routinely in hospitals worldwide. Therefore, Adachi et al. [2] classified the level of lymph nodes metastasis as level I nodes (perigastric 1-6), level II nodes (intermediate 7-9) and level III nodes ( distant 10-16) of the tumor location.

Some japanese authors clarified that not the anatomical level but the total number of positive LN (1-6 vs $\geq 7$ ) was an independent prognostic indicator for $\mathrm{N}+$ gastric cancer [2]. Many authors have suggested that the extended lymphadenectomy D2 or even D3, has potential for a more appropriate pathological staging, better regional disease control and survival advantage [6-8]. The degree of curative efficacy of the lymphadenectomy will remain unknown until prospective randomised trials show evidence of disease control and survival $[9,10]$.
In Europe and in USA, extended lymph nodes dissection is not randomly performed despite the fact that more than $50 \%$ of patients with gastric resection for carcinoma show $\mathrm{N}+$ disease $[11,12]$. In the TNM system, the number of LN to be removed and examined for adequate staging is unclear, varying from 10 to 15 or grater than 25 [13-15]. In JSCA, an extended lymphadenectomy is mandatory for $\mathrm{N}$-stage classification [5]. The rate of "stage migration" for both systems is over $15 \%$ [16-18]. In current opinion, the absolute number of metastatic locoregional lymph nodes (TNM-N category) is the most reliable prognostic indicator for patients with radically resected gastric cancer [19-21]. The UICC/AJCC classification, which is the most widely used for the staging of gastric cancer, suggests that at least $15 \mathrm{LN}$ should be examined for a correct assessment of $\mathrm{N}$ category and this implies that D1 dissection, limited to the level I (1-6 group, perigastric), LN might not guarantee an accurate staging, but D1-lymphadenectomy is routinely performed in Europe, which is supported by the fact that D2 dissection is associated with higher rates of postoperative morbidity and mortality [14,22-26]. 


\section{Cancer Therapy \& Oncology International Journal}

The ratio between metastatic and examined lymph nodes (N-ratio) has been recently proposed, for identifying prognostic subgroups among patients with N1 and N2 disease and reduce the phenomenon of stage migration $[17,21,26-30]$. The aims of our study were to validate the value in prognostic of $\mathrm{N}$ ratio, compared to traditional prognostic systems and to see whether the $\mathrm{N}$ ratio has a prognostic power in patients with limited (D1) lymphadenectomy. The incidence of gastric cancer has decreased over the past 30 years, the disease remains the second leading cause of cancer death [31]. Today, surgery is the only pottentialy curative treatment for gastric cancer. Lymph node metastasis occur during the early stages of the disease and lymphadenectomy is recommended as a main component of radical surgery. The extent of lymphadenectomy has been a controversial topic for a long time without a worldwide consensus as yet. In the 1960s, japanese surgeons firs introduced the extended lymphadenectomy procedure (D2) with systematic dissection of LN in the first tier (D1) and in the second tier (D2). In addition to D2 lymphadenectomy, LN around the upper abdominal aorta are dissected (D3) on the basis that $20 \%$ to $30 \%$ of patients with not-early gastric cancer $(>\mathrm{T} 1)$ had microscopic metastasis present in para-aortic nodes [32-35]. In the present study, we retrospectively evaluated the prognostic significance of the NR in 124 gastric cancer patients.

\section{Patients and Methods}

In this study 124 patients with gastric cancer admitted between 1998 and 2007 were included. D1 lymphadenectomy was performed in 100 patients and 24 D2 lymphadenectomy, according to JSCA and UICC recomandations.

For comparative purposes we classified all patients by three staging systems:

i. JSCA: p0, pn1, pn2, pn3;

ii. UICC/AJCC/TNM: pN0, pN1, pN2, pN3;

iii. NR: NR0(ratio 0\%), NR1(ratio $\leq 20 \%$ ), NR2 (ratio>20\%).

\section{Lymph Node Status Classification}

The 124 evaluated patients were divided into two groups according to the number of examined LN: Group 1 consisted of 98 patients with less than $15 \mathrm{LN}$ and 26 patients with more than $15 \mathrm{LN}$ were in group 2. Lymph node involvement was classified according to both the 1997 UICC/AJCC TNM classification (N0: no metastasis, N1: 1-6 LN+, N2: 7-15 LN+, N3: more than 15 $\mathrm{LN}+)$ and the 1981 JRSC classification (n0= no $\mathrm{LN}+, \mathrm{n} 1=\mathrm{LN}+$ to group $\mathrm{N} 1, \mathrm{n} 2=\mathrm{LN}+$ to group $\mathrm{N} 2, \mathrm{n} 3=\mathrm{LN}+$ to group N3). The medium number of involved LN was 50 ( mean $10 \pm 11$ ).

N-ratio: In survival and stage migration analysis, the NR parameter was the best cut off approach in terms of the logrank test. Rate of stage migration was calculated to each staging system; for this evaluation only perigastric lymph nodes (N1 station) were considered (D1-lymphadenectomy).

\section{Statistical Analysis}

Overall survival (OS) rates and 95\% confidence intervals were determined using the Kaplan - Meier estimation (cit 16). Were analysed: age $<70$ years, age $>70$ years, tumor site, type of surgical resection, T-category (T1: mucosa or submucosa invasion; T2: muscularis propria or subserosa; vs T3: serosa; vs T4: infiltration of extra-gastric space), grading: G1 vs G2 vs G3 vs G4, Lauren type, anatomical location of LN+ (n0 vs n1 vs n2 vs n3), number of LN+ (TNM:N0 vs N1 vs N2 vs N3), N-Ratio between metastatic LN and examined LN (N-Ratio 0 vs N-Ratio 2 vs N-Ratio 3). The Cox's proportional hazard model was used for multivariate survival analysis [36,37]. Value of $p<0.05$ was considered significant and for NR the calculation was by the Pearson correlation coefficient ( $\mathrm{r}$ ).

\section{Results}

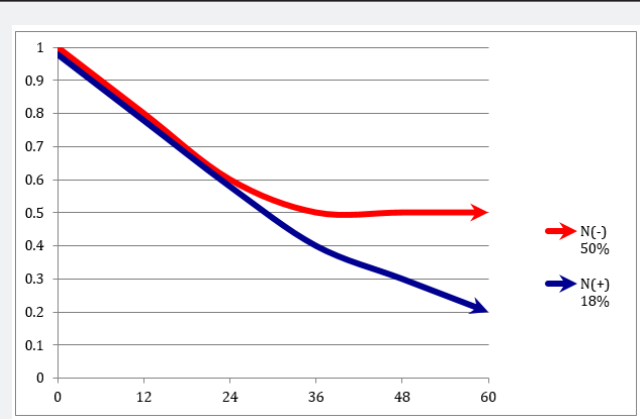

Figure 1: The survival of patients with resected gastric cancer: effect of lymph nodes status.

Table 1: Date of clinical and histopathological records for the 124 patients, 5-year survival rates.

\begin{tabular}{|c|c|c|c|c|c|}
\hline & & $\begin{array}{c}\text { Cases } \\
\mathrm{n}=124\end{array}$ & $\begin{array}{c}\text { 5-year } \\
\text { survival } \\
(\%)\end{array}$ & SE & $P$ \\
\hline \multirow{2}{*}{$\begin{array}{c}\text { Tumor } \\
\text { diameter }\end{array}$} & $\leq 4,0 \mathrm{~mm}$ & 44 & 46 & 4.5 & \multirow{2}{*}{$<0.0001$} \\
\hline & $\geq 4,0 \mathrm{~mm}$ & 80 & 30 & 5.1 & \\
\hline \multirow{2}{*}{$\begin{array}{l}\text { Lauren } \\
\text { type }\end{array}$} & Difuz & 48 & 36 & 5.2 & \multirow{2}{*}{0.049} \\
\hline & Intestinal & 76 & 48 & 5.4 & \\
\hline \multirow{2}{*}{ Grading } & G1-2 & 34 & 50 & 6.9 & \multirow{2}{*}{$<0.0001$} \\
\hline & G3 & 90 & 39 & 4.5 & \\
\hline \multirow{2}{*}{$\begin{array}{c}\text { Residual } \\
\text { tumor } \\
(\mathrm{R})\end{array}$} & R0 & 90 & 49 & 3.7 & \multirow{2}{*}{$<0.0001$} \\
\hline & R1-2 & 34 & 15 & 6.7 & \\
\hline \multirow{4}{*}{$\begin{array}{c}\text { PN AJCC/ } \\
\text { TNM }\end{array}$} & N0 & 12 & 50 & 5 & \multirow{2}{*}{$<0.0001$} \\
\hline & N1 & 76 & 46 & 8.2 & \\
\hline & N2 & 76 & 18 & - & \\
\hline & N3 & - & - & - & \\
\hline NR & NR0 & 14 & 50 & 5 & $<0.0001$ \\
\hline
\end{tabular}

Classification of $\mathrm{N}$ and the elements for survival: For all 124 patients, the 5 -year survival rate was $28 \%$ and in $\mathrm{N}$ negative patients was $50 \%, 18 \%$ for node-positive patients $(\mathrm{P}<0.0001)$ figure 1. In Table 1 are shown the clinical and histopathological record of 124 patients and the 5-year survival rates. In this study, 


\section{Cancer Therapy \& Oncology International Journal}

the tumor diameter, G grading, pT, residual tumor and TNM-stage were the most important prognostic factors. Lauren classification is important on survival, the patients with intestinal type having a significantly higher survival rate. The 5-year survival rates of the patients staged by UICC AJCC pN classification were $46 \%$ to $\mathrm{pN} 1,18 \%$ for $\mathrm{pN} 2$. In the classification by the ratio based $\mathrm{pN}$ classification, the 5-year survival rate was: $39 \%$ for NR1 and $18 \%$ for NR2. Both the NR1 and the NR2 groups in the ratiobased classification system discriminated patients who would have been included in different prognostic categories according to the JSCA and TNM classifications (Table 2). About the survival, we have a statistically significant differences between patients with a different NR stage (for $n 1$ patients: NR1/NR2 $\mathrm{p}<0,0001$, for $n 2$ : NR1/NR2 with $\mathrm{p}=0,002$ ) and $\mathrm{pN}$ stage (for $\mathrm{n} 1$ : NR1 versus NR2 with $\mathrm{p}=0,014$ ).

Table 2: NR distribution, among TNM and JSCA staging systems in N.

\begin{tabular}{|c|c|c|c|}
\hline \multirow{2}{*}{} & & \multicolumn{2}{|c|}{ NR } \\
\cline { 2 - 4 } & & NR1 & NR2 \\
\hline \multirow{3}{*}{ TNM } & N1 & 38 & 9 \\
\cline { 2 - 4 } & $\mathrm{N} 2$ & 6 & 12 \\
\cline { 2 - 4 } & $\mathrm{N} 3$ & - & - \\
\hline \multirow{3}{*}{$7 G C A$} & $\mathrm{~N} 1$ & 28 & 11 \\
\cline { 2 - 4 } & $\mathrm{N} 2$ & 12 & 24 \\
\cline { 2 - 4 } & $\mathrm{N} 3$ & - & - \\
\hline
\end{tabular}

In multivariate analysis, including prognostic factors, NR, pT and S-grading were found to be independent prognostic factors. No correlation was found between the number of total harvested LN and NR ( $r=0,07 ; p=0,3)$, but there was a significant correlation between the number of $\mathrm{N}+\mathrm{LN}$ and the NR $(\mathrm{r}=0,8 ; \mathrm{p}<$ 0,0001).

\section{Discussion}

This study confirmed that N-Ratio has a prognostic value independent of both traditional prognostic factors and extent of lymphadenectomy ( $\leq 15 \mathrm{LN}$ or $\geq 15 \mathrm{LN}$ ). Several staging systems for LN-metastasis considering the level and number of positive nodes were assessed using multivariate analysis and the most important LN informations associated with survival was determinated using multivariate analysis [38-40]. The results indicated that 5-year survival rate significantly decreased when the number of positive level II nodes (N2) was greater than one [40]. Multivariate analysis confirmed that survival rate was significantly influenced by the anatomical level of $\mathrm{N}+\mathrm{LN}$, total number of $\mathrm{N}+$, number of $\mathrm{N}+$ level I nodes and number of $\mathrm{N}+$ level II nodes.The multivariate analysis clarified that the number of positive level I and level II nodes was the most important prognostic indicator in patients with node-positive gastric cancer [41-43].

Recent studies demonstrated that the TNM classification (UICC/AJCC) based on the total number of positive LN is a better staging system compared with the japanese classification based on the anatomical level of lymph node metastasis [44]. The efficacy of LN-dissection in gastric cancer is still controvesial [45-47]. The JSCA nodal staging is considered by western surgeons and pathologists too complicated for clinical use, on the other hand, the UICC/AJCC TNM system, even though easily reproductible, may be influenced by the surgeon's attitude with respect to nodal dissection and by the pathologist examination $[48,49]$. Both staging systems imply the phenomenon of stage migration in a significant percentage of cases $[16,17]$. The lymph node ratio (NR) is becoming increasingly considered as an important prognostic factor in gastric cancer after curative resection and has been proposed as an alternative LN staging system for reducing the stage migration rate $[16,17,46]$.

Many published studies compared the prognostic impact and stage migration rate of JSCA and UICC/AJCC LN classifications with the NR in resectable gastric cancer with curative intent gastrectomy. Our data agree with authors studies, indicating that the NR is a powerful prognostic parameter following resection of gastric cancer. Multivariate stepwise Cox regression analysis of all three lymph nodes classifications togheter, revealed that only the NR is an independent prognostic value ( $p=0,0002)$, our data agree with this results from USA and western and japanese studies $[50,51]$. The data from Wagner et al, in agreement with our study with in vivo and ex vivo lymphography showing that the number of perigastric and celiac LN has great anatomical variations.

Some studies show a direct relationship between the NR and the number of $\mathrm{N}+$ but this correlation don't exists between the NR and total number of harvested LN. Today is unknown the reason why the NR is an independent prognostic factor as proposed by Bando et al. [17], these findings suggest that the NR may reflect the interaction between the lost immune defence mechanism (tumor agressiveness, number of $\mathrm{N}+$ as the numerator), and the total number of dissected LN as the denominator. Some studies observe increased survival in presence of larger number of removed nodes, explained by introducing the concept of stage migration. In Japan, surgeons usually dissect as many LN as possible while in western hospitals, systematic lymphadenectomy (D2 \pm D3) is not routinely performed.

\section{Conclusion}

One great advantage of extensive lymph node dissection $(>15$ $\mathrm{LN}$ ) is that it allows improved staging of the disease and this is of utmost importance when survival rate in different series is compared. Lymphadenectomy is the only prognostic factor that can be influenced by the surgeon. The prognostic impact of the NR is less influenced by the number of dissected nodes and by the individual dotation of lymphatics. The NR may be considered a simple reproductible staging system at institutions.

\section{References}

1. Okusa T, Nakane Y, Boku T, Takada H, Yamamura M, et al. (1990) Quantitative analysis of nodal involvement with respect to survival rate after curative gastrectomy for carcinoma Surgery, Gynecology \& Obstetrics 170(6): 488-494. 


\section{Cancer Therapy \& Oncology International Journal}

2. Adachi Y, Kamakura T, Mori M, Baba H, Maehara Y, et al. (1994) Prognostic significance of the number of positive lymph nodes in gastric carcinoma The British Journal of Surgery 81(3): 414-416.

3. de Manzoni G, Verlato G, Guglielmi A, Laterza E, Genna M, et al. (1996) Prognostic significance of lymph node dissection in gastric cancer. Br J Surg 83(11): 1604-1607.

4. Cheong JH, Hyung WJ, Shen JG, Song C, Kim J, et al. (2006) The N ratio predicts recurrence and poor prognosis in patients with node-positive early gastric cancer Annals of Surgical Oncology 13(3): 377-385

5. Japanese Gastric Cancer Association (1998) Japanese Classification of Gastric Carcinoma - $2^{\text {nd }}$ English Edition. Gastric Cancer 1(1): 10-24.

6. Roder JD, Böttcher K, Siewert JR, Busch R, Hermanek P, et al. (1993) Prognostic factors in gastric carcinoma. Results of the German Gastric Carcinoma Study 1992 Chirurgische Klinik, Technischen Universität München, Germany. Cancer 72(7): 2089-2097.

7. Yokota T, Ishiyama S, Saito T, Teshima S, Narushima Y, et al. (2004) Lymph node metastasis as a significant prognostic factor in gastric cancer: a multiple logistic regression analysis. Scand J Gastroenterol 39(4): 380-384.

8. Kodera Y, Schwarz RE, Nakao A (2002) Extended lymph node dissection in gastric carcinoma: where do we stand after the Dutch and British randomized trials? Journal of the American College of Surgeons 195(6): 855-864.

9. Cuschieri A, Weeden S, Fielding J, Bancewicz J, Craven J, et al. (1999) Patient survival after D1 and D2 resections for gastric cancer: longterm results of the MRC randomized surgical trial British Journal of Cancer 79(9-10): 1522-1530.

10. Bonenkamp JJ, Hermans J, Sasako M, van de Velde CJ, Welvaart K, et al. (1999) Extended Lymph-Node Dissection for Gastric Cancer N Engl J Med 340(12): 908-914.

11. Wanebo HJ, Kennedy BJ, Chmiel J, Steele, D Winchester, et al. (1993) Cancer of the stomach. A patient care study by the American College of Surgeons. Ann Surg 218(5): 583-592.

12. Hundhal SA, Menck HR, Mansour EG, Winchester DP (1997) The national cancer data base report on gastric carcinoma Cancer 80(12): 2333-2341.

13. Siewert JR, Bottcher K, Stein HJ (1998) Relevant Prognostic Factors in Gastric Cancer Annals of Surgery 228: 449-461.

14. Bouvier AM, Haas O, Piard F, Roignot P, Bonithon-Kopp C, et al. (2002) How many nodes must be examined to accurately stage gastric carcinomas? Cancer 94(11): 2862-2866

15. Lee HK, Yang HK, Kim WH, Lee KU, Choe KJ, et al. (2001) Influence of the number of lymph nodes examined on staging of gastric cancer. Br J Surg 88(10): 1408-1412.

16. Nitti D, Marchet A, Olivieri M, Ambrosi A, Mencarelli R, et al. (2003) Ratio between metastatic and examined lymph nodes is an independent prognostic factor after D2 resection for gastric cancer: analysis of a large European monoinstitutional experience. Ann Surg Oncol 10(9): 1077-1085.

17. Bando E, Yonemura Y, Taniguchi K, Fushida S, Fujimura T, et al. (2002) Outcome of ratio of lymph node metastasis in gastric carcinoma Annals of Surgical Oncology 9(8): 775-784

18. Xi Wang X, Wan F, Wang JJ (2008) A Common Misuse of Stepwise Regression in Studies of Ratio of Metastatic Lymph Nodes for Gastric Cancer. Ann Surg Oncol 15(6): 1805-1806.

19. Hohenberger P, Gretschel S (2003) Gastic cancer. The Lancet 362(9380): 305-312.

20. Dicken BJ, Bigam DL, Cass C, Mackey JR, Joy AA, et al. (2005) Gastric adenocarcinoma: review and considerations for future directions. Ann Surg 241(1): 17-29.
21. Siewert JR, Stein HJ, Roder J Chirurgie, Berlin-London (2010) cap V Sobin LH, Wittekind CH International Union Against Cancer (UICC): TNM Classification of Malignant Tumors $5^{\text {th }}$ ed. John Wiley \& Sons, New York, USA.

22. Greene FL, Page DL, Fleming ID, et al. AJCC Cancer Staging Manual ( $6^{\text {th }}$ edn), Springer-Verlag, New York, USA.

23. Wanebo HJ, Kennedy BJ, Winchester DP, Fremgen A, Stewart AK (1996) Gastric Cancer: Does lymph node dissection alter the survival? J Am Coll Surg 183(6): 616-624.

24. Jansen EP, Boot H, Verheij M, van de Velde CJ (2005) Optimal locoregional treatment in gastric cancer. J Clin Oncol 23(50): 4509_ 4517.

25. Siewert JR Surgical Oncology Ed. Springer-Verlag-Berlin 2011.

26. Bunt AM, Hermans J, Smit VT, van de Velde CJ, Fleuren GJ, et al. (1995) Surgical/pathologic-stage migration confronts comparisons of gastric cancer survival rate between Japan and Western countries J Clin Oncol 13(1): 19-25.

27. Inoue K, Nakane Y, Iiyama H, Sato M, Kanbara T, et al. (2002) The superiority of ratio-based lymph node staging in gastric carcinoma. Ann Surg Oncol 9(1): 27-34.

28. Hyung WJ, Noh SH, Yoo CH, Huh JH, Shin DW, et al. (2002) Prognostic significance of metastatic lymph node ratio in $\mathrm{T} 3$ gastric cancer world J Surg 26: 323-329.

29. Kodera Y, Yamamura Y, Shimizu Y, Torii A, Hirai T, et al. (1998) Lymph node status assessment for gastric carcinoma: is the number of metastatic lymph nodes really practical as a parameter for $\mathrm{N}$ categories in the TNM classification? J Surg Oncol 69(1): 15-20.

30. Jemal A, Siegel R, Ward E, Murray T, Xu J, et al. (2006) Cancer statistics. Cancer J clin 56(2): 106-130.

31. Kunisaki C, Shimada H, Yamaoka H, Wakasugi J, Takahashi M, et al (1999) Significance of para-aortic LN-disection in advanced gastric cancer. Hepatogastroenterology 46(28): 2635-2642.

32. Higgins JPT, Green G (Eds) Cohrane Handbook for systemic review of interventions UK Wiley 2006.

33. Degiuli M, Sasako M, Calgaro M, Garino M, Rebecchi F, et al. (2004) Morbidity and mortality after D1 or D2 gastrectomy for gastric cancer. J Surg Oncol 30(3): 303-308.

34. Kulig J, Popiela T, Kolodziejczyk P, Sierzega M, Szczepanik A, et al. (2007) Standard D2 versus extended D2 (D2+) lymphadenectomy for gastric cancer. Am J Surg 193(1): 10-15.

35. Kunisaki C, Shimada H, Nomura M, Matsuda G, Otsuka Y, et al. (2005) Clinical impact of metastatic lymph node ratio in advanced gastric cancer. Anticancer Res 25(2B): 1369-1376.

36. Dicken BJ, Bigam DL, Cass C, Mackey JR, Joy AA, et al. (2005) Gastric adenocarcinoma: review and considerations for future directions. Ann Surg 241(1): 27-39.

37. Roukos DH, Paraschou P, Lorenz M (2000) Distal gastric cancer and extensive surgery. Ann Surg Oncol 7(10): 719-726.

38. Yoshikawa T, Sasako M, Sano T, Nashimoto A, Kurita A, et al. (2006) Stage migration caused by D2 dissection with para-aortic lymphadenectomy for gastric cancer British Journal of Surgery 93(12): 1526-1529.

39. Jakab F, Baranyai L, Baranyai Z, Országh A, Mayer A, et al. (2007) Lymphadenectomy in gastrointestinal surgery for malignancy Acta chir Hung 36(1-4): 141-142.

40.Wu CW, Chang IS (2006) Complications following D3 gastrectomy World J Surg 30: 12-16.

41. Wu CW, Hsiung CA, Lo SS, Hsieh MC, Chen JH, et al. (2005) Stage migration influences on stage-specific survival comparison between D1 and D3 gastric cancer surgeries Eur J Surg Oncol 31(2): 153-157. 


\section{Cancer Therapy \& Oncology International Journal}

42. Hartgrink HH, van de Velde CJ, Putter H, Bonenkamp JJ, Klein Kranenbarg E, et al. (2004) Extended Lymph Node Dissection for Gastric Cancer: who may benefit? Final results of the randomized Dutch gastric cancer group trial. J clin Oncol 22(11): 2069-2077.

43. Roder JD, Böttcher K, Busch R, Wittekind C, Hermanek P, et al (1998) Classification of regional lymph node metastasis from gastric carcinoma Cancer 82(4): 621-631.

44. Higashi $H$, Natsugoe $S$, Ishigami $S$, Uenosono $Y$, Matsumoto $M$ et al. (2003) Distribution of Lymph Node Metastasis Including Micrometastasis in Gastric Cancer with Submucosal Invasion. World J Surg 27(4): 455-459.

45. Kunisaki C, Akiyama H, Nomura M, Matsuda G, Otsuka Y (2005) Surgical outcomes for early gastric cancer in the upper third of the stomach. Am Coll Surg 200(1): 15-19.

46. Kunisaki C, Shimada H, Nomura M, Akiyama H (2001) Appropriate lymph node dissection for early gastric cancer based on lymph node metastases. Surgery 129(2): 153-157.
47. Peter A Davisa, Takeshi Sano (2001) The difference in gastric cancer between Japan, USA and Europe Critical Reviews in Oncology/ Hematology 40(1): 77-94.

48. Sayegh ME, Sano T, Dexter S, Katai H, Fukagawa T, et al. (2004) TNM and and Japanese staging systems for gastric cancer Gastric Cancer 7(3): 140-148.

49. Cuschieri A, Weeden S et al. (1991) Optimal locoregional treatment of gastric cancer Br 7 Cancer 79: 1522-1540.

50. Jansen EP, Boot H (2005) Patient survival after D1 and D2 resection for gastric cancer. J clin Oncol 23: 4509-4511.

51. Wagner PK, Ramaswamy A, Rüschoff J, Schmitz-Moormann P, et al (1991) Lymph node counts in the upper abdomen: anatomical basis for lymphadenectomy in gastric cancer. Br J Surg 78(7): 825-827.
Your next submission with Juniper Publishers will reach you the below assets

- Quality Editorial service

- Swift Peer Review

- Reprints availability

- E-prints Service

- Manuscript Podcast for convenient understanding

- Global attainment for your research

- Manuscript accessibility in different formats

( Pdf, E-pub, Full Text, Audio)

- Unceasing customer service

Track the below URL for one-step submission https://juniperpublishers.com/online-submission.php 